\title{
INFLUÊNCIA DE SANIFICANTES NAS CARACTERÍSTICAS MICROBIOLÓGICAS, FÍSICAS E FÍSICO-QUÍMICAS DE CEBOLA (Allium cepa L.) MINIMAMENTE PROCESSADA
}

\author{
Effect of sanitizers on the microbial, physical and physical-chemical \\ characteristics of fresh-cut onions (Allium cepa $L$ )
}

\author{
Karla Michalsky Carvalho Beerli ${ }^{1}$, Eduardo Valério de Barros Vilas Boas ${ }^{2}$, Roberta Hilsdorf Piccoli $^{2}$
}

\begin{abstract}
RESUMO
Objetivou-se com esta pesquisa avaliar a influência dos sanificantes peróxido de hidrogênio $\left(\mathrm{H}_{2} \mathrm{O}_{2}\right)$ e dicloro isocianurato de sódio (NaDCC) sobre a vida de prateleira da cebola (Allium cepa L.) minimamente processada, com base no desenvolvimento da microbiota e características físicas e físico-químicas. As cebolas foram previamente lavadas, descascadas e fatiadas. Foram testados 6 tratamentos em 3 blocos casualizados. Os tratamentos foram: controle, $\mathrm{H}_{2} \mathrm{O}_{2}(2 \%), \mathrm{H}_{2} \mathrm{O}_{2}(4 \%), \mathrm{H}_{2} \mathrm{O}_{2}(6 \%)$, NaDCC (50ppm) e NaDCC (100ppm). Após a sanificação, as cebolas foram embaladas e armazenadas durante 7 dias a $4^{\circ} \mathrm{C}$. A cada dia, uma bandeja de cada tratamento foi retirada e utilizada para coleta de amostras, para realização das seguintes análises: contagem padrão de microrganismos aeróbios mesófilos, contagem total de microrganismos aeróbios psicrotróficos, quantificação de fungos e leveduras, quantificação de coliformes a $35^{\circ} \mathrm{C}$ e a $45^{\circ} \mathrm{C}$, sólidos solúveis totais (SST), pH, determinação da acidez total titulável (ATT), textura e perda de massa. Menores contagens de aeróbios mesófilos foram encontradas nos tratamentos com $\mathrm{H}_{2} \mathrm{O}_{2}$; todos os tratamentos, exceto o controle, foram eficientes para redução dos aeróbios psicrotróficos e coliformes a $35^{\circ} \mathrm{C}$; não foram encontrados coliformes a $45^{\circ} \mathrm{C}$ em nenhum dos tratamentos; apenas os tratamentos com $4 \%$ e $6 \%$ de $\mathrm{H}_{2} \mathrm{O}_{2}$ reduziram os valores de fungos e leveduras; não houve diferenças entre os tratamentos para as análises de SST e perda de massa; foram obtidos maiores valores de $\mathrm{pH}$ para os tratamentos com NaDCC; menores valores de ATT foram encontrados nos tratamentos com $\mathrm{H}_{2} \mathrm{O}_{2}(4 \%), \mathrm{H}_{2} \mathrm{O}_{2}(6 \%)$ e NaDCC $(50 \mathrm{ppm})$ e maiores resultados de textura foram obtidos nos tratamentos com $\mathrm{H}_{2} \mathrm{O}_{2}$ (4\%) e $\mathrm{H}_{2} \mathrm{O}_{2}(6 \%)$. De acordo com as condições deste experimento, concluiu-se que o $\mathrm{H}_{2} \mathrm{O}_{2}$, nas concentrações de $4 \%$ e $6 \%$, foi mais eficiente como sanificante para cebolas minimamente processadas do que o NaDCC; segundo os parâmetros analisados, a qualidade da cebola se manteve adequada para o consumo em todos os tratamentos até o sétimo dia após o processamento, incluindo o tratamento-controle (sem sanificante).
\end{abstract}

Termos para indexação: Cebola, processamento mínimo, sanificantes, microrganismos.

\section{ABSTRACT}

The goal of this work was to evaluate the effect of hydrogen peroxide $\left(\mathrm{H}_{2} \mathrm{O}_{2}\right)$ and sodium dichloroisocianurate $(\mathrm{NaDCC})$ sanitizers on the shelf-life of fresh-cut onion, based on the microbial development and physical and physical-chemical characteristics. The onions were washed, peeled and sliced. The following treatments were tested using three randomized blocks: $\mathrm{H}_{2} \mathrm{O}_{2}(2 \%), \mathrm{H}_{2} \mathrm{O}_{2}(4 \%), \mathrm{H}_{2} \mathrm{O}_{2}(6 \%), \mathrm{NaDCC}(50 \mathrm{ppm})$ and $\mathrm{NaDCC}(100 \mathrm{ppm})$. The slices were packed and stored at $4^{\circ} \mathrm{C}$ for 7 days, after sanitation. One package for treatment was used daily and the following variables were evaluated: standard counting of mesophile aerobic microorganisms, total counting of psychrotrophs aerobic microorganisms, moulds and yeasts, total coliforms at $35^{\circ} \mathrm{C}$ and $45^{\circ} \mathrm{C}$, total soluble solids (TSS), $\mathrm{pH}$, titratable acidity (TA), firmness and mass loss. Lower counting of mesophile aerobic were found in slices treated with $\mathrm{H}_{2} \mathrm{O}_{2}$; all treatments, but control, were effective in decreasing psychrotroph aerobic and total coliforms at $35^{\circ} \mathrm{C}$; coliforms $45^{\circ} \mathrm{C}$ were not found in slices of any treatment; only $\mathrm{H}_{2} \mathrm{O}_{2}(4 \%)$ and $\mathrm{H}_{2} \mathrm{O}_{2}(6 \%)$ treatments decreased the values of moulds and yeasts; the treatments did not affect the TSS and mass loss; NaDCC treatments promoted higher $\mathrm{pH}$; lower TA were found in slices treated with $\mathrm{H}_{2} \mathrm{O}_{2}(4 \%), \mathrm{H}_{2} \mathrm{O}_{2}(6 \%)$ and $\mathrm{NaDCC}(50 \mathrm{ppm})$ and higher firmness were obtained in slices treated with $\mathrm{H}_{2} \mathrm{O}_{2}(4 \%)$ and $\mathrm{H}_{2} \mathrm{O}_{2}(6 \%)$. From the results it is concluded that $\mathrm{H}_{2} \mathrm{O}_{2}(4$ and $6 \%)$ was more effective sanitizer for fresh-cut onions than NaDCC; according the analyzed parameters, the fresh-cut onion was held in proper edible conditions for 7 days after processing, including the control (without sanitizer).

Index terms: Onion, minimally processed, sanitizers, microorganisms.

(Recebido para publicação em 7 de fevereiro de 2003 e aprovado em 23 de abril de 2003)

\footnotetext{
1. Mestrado em Microbiologia de Alimentos na UFLA

2. Doutorado em Ciência e Tecnologia de Alimentos, professores do Departamento de Ciência dos Alimentos da Universidade Federal de Lavras/UFLA - Caixa Postal 37 - 37200-000 - Lavras, MG
} 


\section{INTRODUÇÃO}

Os produtos minimamente processados fazem parte de um segmento da indústria de horticultura que vem obtendo crescente participação no mercado de produtos frescos e servem como oportunidade interessante aos produtores de hortaliças. No Brasil, a utilização desses produtos teve início no princípio da década de 1990 e seu consumo vem aumentando consideravelmente. Isso porque as hortaliças e frutos minimamente processados oferecem inúmeros benefícios ao consumidor, tais como: redução do tempo de preparo da refeição, maior padronização, maior acesso a frutos e hortaliças frescos e mais saudáveis, menor espaço para estocagem, embalagens de armazenamento facilitado e redução do desperdício e da manipulação pelo consumidor.

Diversos trabalhos de pesquisa têm sido desenvolvidos com o objetivo de estender a vida de prateleira de frutos e hortaliças minimamente processadas. Entretanto, o sucesso desse empreendimento depende do uso de matérias-primas de alta qualidade, manuseadas e processadas em boas condições de higiene.

A cebola é considerada um dos condimentos mais importantes do Brasil, o que assegura sua importância do ponto de vista econômico e seu consumo por todo o País. Quando processada manualmente, sendo cortada ou picada, libera substâncias que irritam os olhos, provocando lacrimejamento, o que torna esse processo indesejável de ser realizado. Nesse sentido, além da rapidez e facilidade de preparo, a oferta de cebola minimamente processada no mercado certamente encontrará campo favorável.

Realizou-se esta pesquisa visando a avaliar a influência dos sanificantes peróxido de hidrogênio $\left(\mathrm{H}_{2} \mathrm{O}_{2}\right)$ e do dicloro isocianurato de sódio (NaDCC) sobre a vida de prateleira da cebola (Allium cepa L.) minimamente processada, com base no desenvolvimento da microbiota e características físicas e físicoquímicas.

\section{MATERIAL E MÉTODOS}

Este trabalho foi desenvolvido nos laboratórios de Microbiologia de Alimentos, Bioquímica de Frutos e no de Microestrutura e Arquitetura Alimentar do Departamento de Ciência dos Alimentos da Universidade Federal de Lavras.

Foram utilizadas cebolas da cultivar Baia Periforme, provenientes do comércio de Lavras, MG, oriundas do Ceasa de Belo Horizonte, MG. Foram escolhidas cebolas de tamanhos semelhantes e sem alteração externa aparente, adquiridas de apenas um fornecedor. Foram comprados cerca de cinco quilos de cebola por repetição.

O delineamento experimental foi em blocos casualizados (DBC), sendo utilizados seis tratamentos e três blocos em tempos distintos, cada um deles com duração de sete dias.

Todos os equipamentos e bancadas foram sanificados com etanol $(70 \%)$. As cebolas foram lavadas com detergente neutro e escovadas para remoção das impurezas superficiais. Posteriormente, foram enxaguadas em água corrente até completa remoção do detergente. Após essa lavagem, as cebolas foram armazenadas em câmara fria, a $4^{\circ} \mathrm{C}$, por $24 \mathrm{~h}$.

Utilizando-se facas, as cebolas foram descascadas e fatiadas com fatiador manual, de modo que a espessura das fatias apresentassem aproximadamente 0,3 $\mathrm{cm}$.

As cebolas foram submetidas a seis tratamentos: controle, $\mathrm{H}_{2} \mathrm{O}_{2} 2 \%$, $4 \%$ e $6 \%$, NaDCC 50 ppm e 100 ppm. No tratamento-controle, não houve adição de nenhum sanificante ou água destilada. Para os tratamentos que utilizaram peróxido de hidrogênio nas concentrações de $2 \%, 4 \%$ e $6 \%$, o tempo de imersão foi de 2 minutos, e para os tratamentos que utilizaram NaDCC a 50 ppm e 100 ppm, o tempo de imersão foi de 5 minutos. Cada tratamento utilizou 5 litros de água destilada previamente autoclavada para o preparo das soluções com sanificantes.

Para cada tratamento foi pesado $1 \mathrm{~kg}$ de cebola fatiada e colocado sobre um pedaço de organza previamente esterilizado em autoclave a $121^{\circ} \mathrm{C}$ por 15 minutos. A cebola, exceto no tratamentocontrole, foi imersa numa solução contendo o sanificante de cada tratamento. Decorrido o tempo de imersão, o excesso de líquido das fatias foi drenado em organza.

Cada um dos 3 blocos utilizados neste experimento foi composto por 6 tratamentos com 8 embalagens por tratamento, totalizando 48 embalagens por bloco. Em cada embalagem foram armazenados aproximadamente $115 \mathrm{~g}$ de cebola fatiada. As embalagens de poliestireno $(13 \mathrm{~cm} \times 10 \mathrm{~cm} \times 5,0 \mathrm{~cm}$ de altura) foram previamente sanificadas com hipoclorito de sódio a 100 ppm e secas em câmara de fluxo laminar por 10 minutos, sob luz ultravioleta. As embalagens foram armazenadas a $4^{\circ} \mathrm{C}$. Para cada tratamento, foi retirada diariamente uma embalagem para realização das análises microbiológicas, físicas e físico-químicas. 
Amostras de 25 g de cebola grupo Baia Periforme foram retiradas aleatoriamente da embalagem e, em seguida, foi feita a homogeneização em $225 \mathrm{ml}$ de água peptonada $0,1 \%(\mathrm{p} / \mathrm{v})$ esterilizada em liquidificador doméstico durante um minuto.

Os microrganismos aeróbios mesófilos foram quantificados pelo método de plaqueamento em profundidade, utilizando alíquotas de $1 \mathrm{ml}$ das diluições adequadas. Utilizou-se o meio ágar para contagem padrão (PCA) e as placas foram incubadas em estufa BOD a $37^{\circ} \mathrm{C}$ por 48 horas. Após esse período, as colônias foram quantificadas e os resultados expressos em unidades formadoras de colônia por grama de cebola (UFC/g). Os microrganismos aeróbios psicrotróficos foram quantificados pelo método de plaqueamento em profundidade, dispensando nas placas alíquotas de $1 \mathrm{ml}$ das diluições adequadas. Utilizou-se o meio ágar para contagem padrão (PCA), sendo as placas incubadas em estufa BOD a $7^{\circ} \mathrm{C}$ por 10 dias. Após esse período, as colônias foram quantificadas, e os resultados, expressos em UFC/g.

Os fungos e as leveduras foram quantificados pelo método de plaqueamento em profundidade, dispensando nas placas alíquotas de $1 \mathrm{ml}$ das diluições adequadas. Utilizou-se meio ágar batata dextrose (BDA) acidificado com ácido tartárico a $10 \%(\mathrm{p} / \mathrm{v})$. As placas foram incubadas em estufa $\mathrm{BOD}$ a $25^{\circ} \mathrm{C}$ por cinco dias e os resultados foram expressos em UFC/g. Após as contagens, os fungos filamentosos foram isolados para identificação do gênero.

Os coliformes a $35^{\circ} \mathrm{C}$ foram quantificados utilizando-se a técnica do número mais provável (NMP). $\mathrm{O}$ teste presuntivo foi realizado com a inoculação de alíquotas de $1 \mathrm{ml}$ das diluições adequadas da amostra em quatro séries de três tubos, contendo tubos de Durhan e o meio de cultura caldo lauril sulfato triptose (LST); os tubos foram incubados em estufa a $35^{\circ} \mathrm{C}$ por 48 horas. Foram considerados tubos positivos para coliformes a $35^{\circ} \mathrm{C}$ aqueles que apresentaram turvação e formação de gás. Os resultados foram expressos em NMP/g.

Os coliformes a $45^{\circ} \mathrm{C}$ foram quantificados usando-se a técnica do NMP. As alíquotas foram transferidas dos tubos positivos do teste presuntivo de coliformes a $35^{\circ} \mathrm{C}$, com auxílio de uma alça de repicagem para tubos contendo o meio de cultura caldo Escherichia coli (EC) adicionados de tubos de Durhan. Os tubos foram incubados em banho-maria a $44,5^{\circ} \mathrm{C}$ por 48 horas e foram considerados positivos aqueles que apresentaram turvação e formação de gás. Os resultados foram expressos em NMP/g.
Para as análises de SST, ATT e pH, para cada tratamento, foram pesadas amostras de $10 \mathrm{~g}$ de cebola e homogeneizadas em $40 \mathrm{ml}$ de água destilada em liquidificador doméstico por 20 segundos. Os SST foram determinados por refratometria, utilizando-se refratômetro digital ATAGO PR-1000. Os resultados foram expressos em graus Brix ( $\left.{ }^{\circ} \mathrm{Brix}\right)$. A ATT das cebolas foi obtida por titulação com hidróxido de sódio $(\mathrm{NaOH})$ a $0,1 \mathrm{~N}$, utilizando-se fenolftaleína como indicador. Os resultados foram expressos em $\mathrm{mg}$ de ácido pirúvico por $100 \mathrm{~g}$ de cebola. Os valores do $\mathrm{pH}$ foram obtidos por potenciometria com eletrodo de vidro, utilizando-se um potenciômetro Digimed, modelo DM-20.

A firmeza foi determinada em um analisador modelo TA.XT2i. A sonda mediu a força de corte na cebola, numa velocidade de $5 \mathrm{~mm} / \mathrm{s}$ e foi devidamente calibrada com a célula de carga, seguindo o procedimento-padrão. Os resultados foram expressos em Newtons (N).

Os valores da perda de massa foram determinados com o auxílio de uma balança semi-analítica Mettler, modelo PC 2000. O peso final da cebola contida em cada bandeja foi subtraído do peso inicial a cada dia do experimento e os resultados foram expressos em gramas.

\section{RESULTADOS E DISCUSSÃO}

A metodologia empregada neste experimento para o uso de sanificantes em cebolas minimamente processadas mostrou-se simples e rápida, facilmente aplicada em situações práticas. Até o fim desse experimento, não foi notada nenhuma alteração aparente na cor ou odor das cebolas. A matéria-prima mostrou baixa contaminação inicial, evidenciada pelos resultados das análises microbiológicas.

Os tratamentos em que foi utilizado o $\mathrm{H}_{2} \mathrm{O}_{2}$ como sanificante diferiram significativamente de todos os outros tratamentos e não diferiram entre si. Portanto, o peróxido de hidrogênio em todas as concentrações utilizadas foi o sanificante mais eficiente para controlar o crescimento de aeróbios mesófilos, independente das concentrações utilizadas.

De acordo com a legislação francesa, (MANZANO et al., 1995), os produtos vegetais para consumo humano devem apresentar contagens de aeróbios mesófilos inferiores a $5 \times 10^{7} \mathrm{UFC} / \mathrm{g}$. As maiores contagens de aeróbios mesófilos encontradas neste trabalho estão na faixa de $10^{5} \mathrm{UFC} / \mathrm{g}$, comprovando uma boa qualidade microbiológica do produto. 
As contagens de microrganismos aeróbios mesófilos e psicrotróficos determinam a qualidade final dos alimentos. Neste experimento, foram encontradas baixas contagens médias de microrganismos aeróbios psicrotróficos, mesmo no tratamento-controle, que alcançou níveis de 1,16 ciclo logarítmico.

De acordo com as médias de microrganismos psicrotróficos apresentadas na Tabela 1, pelos resultados, verifica-se que todos os sanificantes utilizados foram eficientes na redução da contagem dos microrganismos psicrotróficos.

Observou-se que somente os tratamentos com $4 \%$ e $6 \%$ de peróxido de hidrogênio diferiram estatisticamente dos demais, sendo eficientes para inibir o desenvolvimento de fungos filamentosos e leveduras ( Tabela 1).

Os resultados de fungos filamentosos e leveduras indicam condições de higiene e refletem a umidade dentro da embalagem. Neste trabalho, apesar de as cebolas terem sido embaladas úmidas, apenas com a drenagem do excesso de líquidos, não houve altas contagens para esse parâmetro.

Os fungos isolados nas cebolas minimamente processadas foram identificados como pertencentes aos gêneros Aspegillus, Penicillium e Cladosporium. A presença desses fungos nas cebolas pode estar relacionada com a contaminação do ambiente em que as mesmas foram manipuladas ou com a contaminação durante a realização das análises microbiológicas.

Com relação à presença de coliformes a $35^{\circ} \mathrm{C}$, os sanificantes utilizados foram efetivos em relação ao tratamento-controle (Tabela 1).

TABELA 1 - Microrganismos aeróbios mesófilos, aeróbios psicrotróficos, fungos e leveduras e coliformes a $35^{\circ} \mathrm{C}$ de cebola grupo Baia Periforme minimamente processada submetida a diferentes sanificantes e armazenada a $4^{\circ} \mathrm{C}$.

\begin{tabular}{|c|c|c|c|c|}
\hline Tratamentos & $\begin{array}{l}\text { Aeróbios mesófilos } \\
\left(\log _{10} 1+\mathrm{UFC} / \mathrm{g}\right)\end{array}$ & $\begin{array}{l}\text { Aeróbios psicrotróficos } \\
\quad\left(\log _{10} 1+\mathrm{UFC} / \mathrm{g}\right)\end{array}$ & $\begin{array}{l}\text { Fungos e leveduras } \\
\left(\log _{10} 1+\mathrm{UFC} / \mathrm{g}\right)\end{array}$ & $\begin{array}{c}\text { Coliformes a } \\
3^{\circ} \mathrm{C}\left(\log _{10}\right. \\
1+\mathrm{NMP} / \mathrm{g})\end{array}$ \\
\hline Controle & $3,58 b$ & $1,16 b$ & $2,17 b$ & $1,48 b$ \\
\hline $\mathrm{H}_{2} \mathrm{O}_{2}(2 \%)$ & $2,60 \mathrm{a}$ & $0,39 a$ & $1,80 \mathrm{~b}$ & $0,50 \mathrm{a}$ \\
\hline $\mathrm{H}_{2} \mathrm{O}_{2}(4 \%)$ & $2,29 \mathrm{a}$ & $0,47 \mathrm{a}$ & $1,18 \mathrm{a}$ & $0,33 \mathrm{a}$ \\
\hline $\mathrm{H}_{2} \mathrm{O}_{2}(6 \%)$ & $2,54 \mathrm{a}$ & $0,11 \mathrm{a}$ & $1,30 \mathrm{a}$ & $0,29 a$ \\
\hline $\mathrm{NaDCC}(50 \mathrm{ppm})$ & $3,11 b$ & $0,42 \mathrm{a}$ & $2,15 b$ & $0,33 \mathrm{a}$ \\
\hline NaDCC (100ppm) & $3,08 b$ & $0,39 a$ & $2,25 b$ & $0,20 \mathrm{a}$ \\
\hline
\end{tabular}

*Médias seguidas da mesma letra não diferem estatisticamente, a $5 \%$ de probabilidade, pelo teste de ScottKnott.

Ciênc. agrotec., Lavras, v. 28, n. 1, p. 107-112, jan./fev., 2004
Em todos os tratamentos houve ausência de coliformes a $45^{\circ} \mathrm{C}$, evidenciando as boas condições higiênico-sanitárias em todas as etapas do processamento da cebola.

Segundo a legislação francesa, (MANZANO et al., 1995), os produtos vegetais para consumo humano devem apresentar contagens de coliformes, a $45^{\circ} \mathrm{C}$, inferiores a $1000 \mathrm{UFC} / \mathrm{g}$.

Os sólidos solúveis totais (SST) expressam os teores de açúcares solúveis, ácidos orgânicos e outros constituintes menores. Os valores médios de SST neste experimento variaram de 6,2 a 6,9, e os sanificantes não alteraram significativamente os teores dessa variável em cebolas minimamente processadas (Tabela 2). A redução do teor de SST durante o armazenamento ocorre, provavelmente, devido ao consumo de substratos no metabolismo respiratório, sendo característica de reações catabólicas de senescência.

A cebola é considerada uma hortaliça ácida. No presente estudo, encontraram-se valores médios de $\mathrm{pH}$ variando de 5,5 a 5,6. Rodas e Torre (2002) encontraram valores de $\mathrm{pH}$ entre 5,2 a 5,5 em diversas variedades de cebolas in natura da cultivar Baia Periforme e, Jay (1986), citado por Germano e Germano (2001), encontrou valores entre 5,3 a 5,8. De acordo com esses dados, somente os tratamentos com NaDCC apresentaram diferenças significativas de $\mathrm{pH}$, apesar de serem irrisórias na prática. Os valores de $\mathrm{pH}$ em todos os trata- 
mentos mantiveram-se praticamente estáveis ao longo do experimento. As pequenas variações no $\mathrm{pH}$ durante $\mathrm{o}$ armazenamento possivelmente ocorreram devido ao efeito tampão exercido pelo fluido celular.

Os valores de $\mathrm{pH}$ encontrados na cebola minimamente processada favorecem a ação do peróxido de hidrogênio, que foi relatado por Block (1991) como sendo mais ativo em $\mathrm{pH}$ ácido. Segundo Germano e Germano (2001), está bem estabelecido que a maioria dos microrganismos desenvolve-se melhor em valores de $\mathrm{pH}$ próximos a 7,0 $(6,6-7,5)$, embora citem que bactérias preferem $\mathrm{pH}$ em torno de 6,0 e 8,0 , fungos entre 3,5 e 4,0 e leveduras em torno de 4,5 e 6,0. Segundo esses dados e de acordo com os resultados deste experimento, apenas as leveduras encontram-se em sua faixa ótima de $\mathrm{pH}$.

Com relação aos resultados de acidez total titulável (ATT), apenas os tratamentos com $4 \%$ e $6 \%$ de $\mathrm{H}_{2} \mathrm{O}_{2}$ e o tratamento com 50 ppm de NaDCC foram significativamente diferentes dos demais (Tabela 2). A maior média da ATT foi $178,8 \mathrm{mg} / 100 \mathrm{~g}$, no tratamento com peróxido de hidrogênio a $2 \%$ e a menor média encontrada foi de $157,0 \mathrm{mg} / 100 \mathrm{~g}$, no tratamento com peróxido de hidrogênio a $6 \%$. Todos os tratamentos, independente da utilização ou não de sanificantes, mostraram uma redução do teor de ATT ao longo do período de armazenamento. Essa redução ocorre normalmente em hortaliças e faz parte do processo de senescência, sendo ocasionada pela possível perda de ácidos orgânicos em virtude da drenagem do líquido celular e volatilização dos ácidos presentes na cebola, principalmente o ácido pirúvico.

Os tratamentos com $4 \%$ e $6 \%$ de peróxido de hidrogênio resultaram numa maior firmeza, o que é desejável, diferindo significativamente dos demais (Tabela 2). Deve-se considerar que as cebolas foram cortadas com fatiador manual e que as diferentes espessuras obtidas e os diferentes graus de maturação fizeram oscilar os resultados de firmeza. A maior média de firmeza foi encontrada no tratamento com peróxido de hidrogênio a $6 \%(30,7 \mathrm{~N})$ e a menor média foi obtida no tratamento com NaDCC a 100 ppm $(20,6 \mathrm{~N})$.

Frutos e hortaliças perdem seu frescor típico e firmeza característica quando são expostas ao armazenamento sob refrigeração, até mesmo por curtos períodos. Essas alterações são aceleradas quando as células são injuriadas, como no descascamento e fatiamento. Apesar de o amolecimento ser uma das principais alterações esperadas em vegetais durante o armazenamento, as cebolas minimamente processadas neste experimento não perderam sua firmeza ao longo do período estudado. Esse é um importante resultado para o processamento desse produto. A manutenção da firmeza das cebolas grupo Baia Periforme MP, neste trabalho, pode estar relacionada com as baixas contagens de microrganismos obtidas, tanto bactérias como fungos e leveduras, pois esses são produtores de enzimas que degradam celulose e/ou pectina da parede celular dos vegetais.

TABELA 2 - Sólidos solúveis totais (SST), pH, acidez total titulável (ATT), firmeza e perda de massa de cebola grupo Baia Periforme minimamente processada submetida a diferentes sanificantes e armazenada a $4^{\circ} \mathrm{C}$.

\begin{tabular}{lccccc}
\hline \multicolumn{1}{c}{ Tratamentos } & $\begin{array}{c}\text { SST } \\
\left({ }^{\mathbf{0}} \mathbf{B r i x}\right)\end{array}$ & $\mathbf{p H}$ & $\begin{array}{c}\text { ATT } \\
(\mathbf{m g} / \mathbf{1 0 0 g})\end{array}$ & $\begin{array}{c}\text { Firmeza } \\
(\mathbf{N})\end{array}$ & $\begin{array}{c}\text { Perda de massa } \\
(\mathbf{g})\end{array}$ \\
\hline Controle & $6,9 \mathrm{a} * *$ & $5,5 \mathrm{a}^{* *}$ & $174,4 \mathrm{~b}^{* *}$ & $26,1 \mathrm{a}^{*}$ & $0,084 \mathrm{a}^{* *}$ \\
$\mathrm{H}_{2} \mathrm{O}_{2}(2 \%)$ & $6,2 \mathrm{a}$ & $5,5 \mathrm{a}$ & $178,8 \mathrm{~b}$ & $24,5 \mathrm{a}$ & $0,072 \mathrm{a}$ \\
$\mathrm{H}_{2} \mathrm{O}_{2}(4 \%)$ & $6,3 \mathrm{a}$ & $5,5 \mathrm{a}$ & $165,7^{\mathrm{a}}$ & $29,8 \mathrm{~b}$ & $0,102 \mathrm{a}$ \\
$\mathrm{H}_{2} \mathrm{O}_{2}(6 \%)$ & $6,4 \mathrm{a}$ & $5,5 \mathrm{a}$ & $157,0^{\mathrm{a}}$ & $30,7 \mathrm{~b}$ & $0,067 \mathrm{a}$ \\
$\mathrm{NaDCC}(50 \mathrm{ppm})$ & $6,3 \mathrm{a}$ & $5,6 \mathrm{~b}$ & $165,8^{\mathrm{a}}$ & $24,8 \mathrm{a}$ & $0,088 \mathrm{a}$ \\
$\mathrm{NaDCC}(100 \mathrm{ppm})$ & $6,4 \mathrm{a}$ & $5,6 \mathrm{~b}$ & $176,6 \mathrm{~b}$ & $20,6 \mathrm{a}$ & $0,077 \mathrm{a}$ \\
\hline
\end{tabular}

*/**Médias seguidas da mesma letra não diferem estatisticamente, respectivamente a 1 e $5 \%$ de probabilidade, pelo teste de Scott-Knott. 
Quanto à perda de massa, não houve diferença significativa em nenhum tratamento, mostrando que os sanificantes utilizados não influenciaram a perda de massa das cebolas (Tabela 1). Um dos principais problemas na vida de armazenamento de muitos frutos e hortaliças é a perda de massa, que está relacionada ao tempo de armazenamento e à transpiração. Essa perda ocorre em função da perda de água, resultando não somente em alterações quantitativas, mas também na aparência (murchamento e enrugamento), nas qualidades texturais (amaciamento, perda de frescor e suculência) e na qualidade nutricional (KADER, 2002).

Além da desidratação, a perda de massa pode ocorrer pela evaporação dos compostos voláteis. Neste trabalho, ocorreu gradativa perda de massa ao longo do armazenamento, mas deve-se ressaltar que essa redução foi mínima, do ponto de vista prático. A maior perda de massa média deste estudo foi encontrada no tratamento com $\mathrm{H}_{2} \mathrm{O}_{2}$ a $4 \%$, que foi de $0,102 \mathrm{~g}$, representando apenas $0,09 \%$ em relação ao peso inicial (115 g).

\section{CONCLUSÕES}

De acordo com as condições deste experimento, concluiu-se que:

a) A qualidade do grupo Baia Periforme se mantém adequada para o consumo em todos os tratamentos, incluindo o tratamento-controle (sem sanificante), armazenada por 7 dias, a $4^{\circ} \mathrm{C}$, em atmosfera modificada, baseado na legislação para hortaliças in natura; b) O peróxido de hidrogênio, nas concentrações de $4 \%$ e $6 \%$, é mais eficiente como sanificante para grupo Baia Periforme minimamente processadas, do que o tratamento-controle e o dicloro isocianurato de sódio.

\section{REFERÊNCIAS BIBLIOGRÁFICAS}

BLOCK, S. S. Peroxygen compounds. In:

Disinfection, sterilization and preservation. 4. ed. London: Seymour, 1991. p. 167-181.

GERMANO, P. M. L.; GERMANO, M. I. S. Higiene e vigilância sanitária de alimentos. São Paulo: Varela, 2001. 628 p.

KADER, A. A. Posthavest biology and technology: an overview. In: Posthavest technology or horticultural crops. 3. ed. California: University of California; Agriculture and Natural Resources, 2002. p. 435-461. (Davis publ., 3311)

MANZANO, M.; CITTERIO, B.; MAIFRENI, M.; PAGANESSI, M.; COMI, G. Microbial and sensory quality of vegetables for soup packaged in different atmospheres. Journal Science of Food Agriculture, Washington, v. 67, n. 4, p. 521-529, 1995.

RODAS, M. A. de B.; TORRE, J. C. de M. D. Avaliação físico-química e sensorial de variedades comerciais de cebolas (Allium cepa L.) in natura. Higiene Alimentar, São Paulo, v. 16, n. 97, p. 56-61, jun. 2002. 